\title{
Synthesis and Characterization of Organic-Inorganic Hybrids Formed Between Conducting Polymers and Crystalline Antimonic Acid
}

\author{
Fábio A. Beleze and Aldo J. G. Zarbin* \\ Departamento de Química, Universidade Federal do Paraná, CP 19081, 81531-990 Curtiba - PR, Brazil
}

\begin{abstract}
Neste trabalho são relatadas e discutidas a síntese e a caracterização de dois materiais híbridos orgânico-inorgânico, formados entre o ácido antimônico cristalino (AAC), como fração inorgânica, e dois polímeros condutores (polipirrol e polianilina) como fração orgânica. Os híbridos foram obtidos a partir da polimerização oxidativa in situ dos monômeros, utilizando-se o próprio AAC como agente oxidante, a partir da redução dos átomos de $\mathrm{Sb}(\mathrm{V})$ presentes em sua estrutura. Os materiais foram caracterizados por espectroscopias infravermelho e Raman, voltametria cíclica, difratometria de raios-X, análise elementar $\mathrm{CHN}$ e espectroscopia de ressonância paramagnética eletrônica. Os resultados evidenciaram que ambos os polímeros foram formados em sua forma oxidada, com a própria estrutura do AAC atuando como contra-íon.
\end{abstract}

In this paper we report the synthesis and characterization of novel organic-inorganic hybrid materials between the crystalline antimonic acid (CAA) and two conductive polymers: polypyrrole and polyaniline. The hybrids were obtained by in situ oxidative polymerization of monomers by the $\mathrm{Sb}(\mathrm{V})$ present in the pyrochlore-like CAA structure. The materials were characterized by infrared and Raman spectroscopy, X-ray diffraction, cyclic voltammetry, CHN elemental analysis and electronic paramagnetic resonance spectroscopy. The results showed that both polymers were formed in their oxidized form, with the CAA structure acting as a counter anion.

Keywords: organic-inorganic hybrid materials, conducting polymers, crystalline antimonic acid

\section{Introduction}

The possibility of combining the properties of organic and inorganic compounds in a unique material is an old challenge. Actually, the research on hybrid organic/inorganic materials is an expanding area in the materials science ${ }^{1-10}$. These hybrids constitute a class of advanced composite materials with unusual properties, which can be used in many fields such as optics, ionics, electronics, mechanics, etc. According to Judeinstein and Sanchez ${ }^{1}$, these hybrid materials can be classified in two groups, based on the nature of the interface between the organic and the inorganic phases: in a first group organic and inorganic compounds are linked only by weak bonds (hydrogen or van der Waals bonds), and in a second group the two phases are linked together through strong chemical (either covalent or ionic) bonds. The chemical interactions between the organic and inorganic phases are very important to understand and evaluate the properties of the hybrid materials.

\footnotetext{
*e-mail: aldo@quimica.ufpr.br
}

One important class of hybrid materials is that in which the organic fraction is composed by conducting polymers ${ }^{11-15}$. Electronically conductive polymers, such as polypyrrole (PPy) and polyaniline (PANI), have been intensively studied ${ }^{16-18}$. Advanced materials based on conducting polymers lead to devices as sensors, transducers, electrochromic and photoelectrochemical devices, LED's, rechargeable batteries, etc. Conducting polymers can be prepared either by chemical or electrochemical oxidation of suitable monomer. Chemical synthesis is usually performed adding the monomer to a oxidant solution $\left(\mathrm{Cu}^{2+}, \mathrm{Fe}^{3+},\left(\mathrm{NH}_{4}\right)_{2} \mathrm{~S}_{2} \mathrm{O}_{8}\right.$, etc. $)$. In the case of polypyrrole, its oxidation potential is lower than that of the monomer (pyrrole) ${ }^{19}$ and thus the polymer is simultaneously oxidized during polymerization. The polymer oxidation produces the carriers called polarons (a radical-cation) and bipolarons (a spinless dication). Consequently, the counteranions present in solution are incorporated into the growing polymer and the polymer is so-called "doped".

The polyaniline general formula is [(-B-NH-B-NH) $\mathrm{y}(\mathrm{B}-$ $\left.\mathrm{N}=\mathrm{Q}=\mathrm{N}-)_{1-\mathrm{y}}\right]_{\mathrm{n}}$, where $\mathrm{B}$ represents a benzoid reduced unit and $\mathrm{Q}$ a quinoid oxidized unit ${ }^{18}$. The $\mathrm{y}$ value can change continuously from 0 to 1 . The conductive form of PANI is 
the half-oxidized form $(y=0,5)$ with the imine nitrogens protonated. This form is called emeraldine salt (ES) and needs a counter-anion (dopant) to neutralize the charges ${ }^{18}$.

In general, the formation of hybrids between conducting polymers and inorganic solids aims to obtain composite materials with synergetic or complementary behaviors between the polymer and the inorganic matrices. The properties of the designed composites will depend both on the characteristics of the polymers and on the nature of the inorganic matrices. This approach can be very useful to obtain materials with predetermined properties.

Several routes to obtain hybrid materials involving conducting polymers are encountered in the literature. The sol-gel process is the most useful synthetic technique ${ }^{20-23}$. Another possibility is the synthesis of nanocomposites, formed by the encapsulation of conducting polymers inside nanometric void spaces of inorganic host materials (such as pores, cavities, tunnels, layers, etc.). In this way, nanocomposites of polypyrrole and polyaniline were prepared with porous glasses ${ }^{11}$, zeolites ${ }^{14}$, layered materials ${ }^{12}$, etc. Two important reviews have been recently published concerning this subject ${ }^{24,25}$.

In this paper we report the synthesis and characterization of two hybrid materials, formed between two conducting polymers (polypyrrole and polyaniline) and the crystalline antimonic acid (CAA). This inorganic material represented by $\mathrm{H}_{2} \mathrm{Sb}_{2} \mathrm{O}_{6} \cdot \mathrm{nH}_{2} \mathrm{O}$ shows protonexchange reactions, exhibits high protonic conductivities and negligible electronic conductivity 26,27 . It has a pyrochlore-like structure, with a characteristic structural feature formed by a $\left[\mathrm{Sb}_{2} \mathrm{O}_{6}{ }^{2-}\right]_{\mathrm{n}}$ three-dimensional framework built up from infinite chains of corner-shared $\mathrm{SbO}_{6}$ octahedra ${ }^{28}$. Water molecules and acidic protons occupy the interconnected interstitial cavities within the framework $^{28}$. The CAA/conducting polymer hybrids obtained in this work can present mixed ionic and electronic conductivities (from CAA and conducting polymers, respectively). Materials with these characteristics have much scientific and technological interest, and can be applied in a great number of devices ${ }^{29}$.

\section{Experimental}

$\mathrm{Sb}_{2} \mathrm{O}_{3}$ (Merck), $\mathrm{H}_{2} \mathrm{O}_{2} 31 \%$ (w/w) solution (Merck), concentrated $\mathrm{HCl}$ solution (Merck) and concentrated $\mathrm{NH}_{4} \mathrm{OH}$ solution (Merck) were used as received. Pyrrole (Aldrich) and aniline (ECIBRA) were distilled before use.

Antimonic acid with pyrochlore structure was synthesized according to Ozawa et $\mathrm{al}^{30}$. A total of $6 \mathrm{~g}$ of $\mathrm{Sb}_{2} \mathrm{O}_{3}$ was oxidized with $120 \mathrm{~mL}$ of $\mathrm{H}_{2} \mathrm{O}_{2}$ with the suspension being stirred at $65^{\circ} \mathrm{C}$ for $30 \mathrm{~h}$. After this the resulting white solid was separated by centrifugation and washed several times with deionized water; finally, it was dried at $40{ }^{\circ} \mathrm{C}$.

The CAA/polypyrrole hybrid was made by adding approximately $0.5 \mathrm{~g}$ of CAA in $10 \mathrm{~mL}$ of pure pyrrole. The dispersion was stirred in air at room temperature for 6 h (CAA/PPy), after which time the color of the solid changed from white to gray. The solid was then separated by centrifugation, washed with ethanol and with deionized water and dried at $40{ }^{\circ} \mathrm{C}$. Another synthesis was carried out as reported above, but the reaction was left for $72 \mathrm{~h}$, in an attempt to increase the amount of polypyrrole. This last procedure, however, was not successful.

The CAA/polyaniline hybrid was obtained by adding approximately $0.1 \mathrm{~g}$ of CAA in $20 \mathrm{~mL}$ of a $2 \mathrm{~mol} \mathrm{~L}^{-1} \mathrm{HCl}$ solution. Aniline ( $4 \mathrm{~mL}$ ) was added to this suspension and the mixture was stirred in air at room temperature for $72 \mathrm{~h}$ (CAA/PANI-1). After approximately $3 \mathrm{~h}$ the solid became green, and this color remained until the end of reaction. The resulting solid was isolated, washed and dried as described above. Another two routes to the CAA/polyaniline hybrid were investigated. Route 1: $0.1 \mathrm{~g}$ of CAA was added to 10 $\mathrm{mL}$ of pure aniline and the suspension was stirred for 2 weeks. The resulting pink solid (CAA/PANI-2) was isolated, washed and dried as described above. Route 2: A beaker containing $0.1 \mathrm{~g}$ of CAA was placed in a desiccator containing a flask with pure aniline. The desiccator was closed and evacuated, aiming to saturate the atmosphere with aniline. After 2 weeks, the pink solid (CAA/PANI-3) was washed with ethanol and dried under vacuum.

Infrared spectra were obtained in a Bomem B-100 spectrometer, series 43178, with $\mathrm{KBr}$ pellets. Each spectrum was collected with 64 scans.

$\mathrm{X}$-ray diffraction (XRD) patterns were obtained with a Phillips diffractometer, using $\mathrm{Cu}-\mathrm{Ka}$ radiation with $40 \mathrm{KV}$ and $20 \mathrm{~mA}$, at a $0.2^{\circ}$ scan rate (in $2 \theta$ ). The room temperature measurements were performed with samples spread on a conventional glass sample holder. Powder silicon reflections were used for $2 \theta$ calibration.

The Raman spectra were obtained in a Renishaw Raman Image Spectrophotometer, coupled to an optical microscope that focused the incident radiation down to an approximately $1 \mathrm{~mm}$ spot. A He-Ne laser (emitting at $632.8 \mathrm{~nm}$ ) was used, with incidence potency of $4 \mathrm{~mW}$. The spectra were obtained with 28 scans, over the $2000-100 \mathrm{~cm}^{-1}$ region.

Cyclic voltametry experiments were measured in $0.1 \mathrm{~mol}$ $\mathrm{L}^{-1} \mathrm{H}_{2} \mathrm{SO}_{4}$ solution (used as electrolyte), using $\mathrm{Ag} / \mathrm{AgCl}$ as reference electrode and a $\mathrm{Pt}$ wire as a counter-electrode. The working electrode was prepared as follows: the hybrid material was suspended in distilled water. This suspension was carefully transferred to the surface of conducting glass electrodes (ITO). 
After water evaporation, at room temperature, one uniform and transparent film was formed on the ITO surface. Measurements were performed using a EG\&G Princeton Applied research potentiostat model 273A. The scan speed was $50 \mathrm{mV} \mathrm{s}^{-1}$ and the potential range from -0.1 to $0.9 \mathrm{~V}$.

The EPR spectra of the samples were obtained in the solid state at room temperature in quartz tubes. A Bruker ESP $300 \mathrm{E}$ spectrometer was used operating at a frequency of $\sim 9.5 \mathrm{GHz}$ (X-band), with a $100 \mathrm{KHz}$ modulation frequency, $2.024 \mathrm{G}$ modulation amplitude and $2 \mathrm{~mW}$ microwave power.

\section{Results and Discussion}

The crystalline antimonic acid (CAA) was fully characterized as described in our previous work ${ }^{26,27}$. Our synthetic route to CAA/PPy and CAA/PANI hybrids consists in employing the CAA to induce the oxidative polymerization, by the reduction of $\mathrm{Sb}(\mathrm{V})$ to $\mathrm{Sb}(\mathrm{III})$. In this case, the CAA structure can act simultaneously as oxidant, dopant and host for the conducting polymer that will grow on the CAA grains surface or inside the CAA cavities.

When pyrrole is added to CAA, the white solid becomes dark gray. This is the first evidence for the occurrence of pyrrole polymerization. CHN elemental analysis indicates that the amount of polymer obtained is around $2.5 \%$ in weight.

Polypyrrole formation was confirmed by Raman spectroscopy. Figure 1 shows the Raman spectra of CAA (a) and CAA/PPy (b). The CAA/PPy spectrum shows bands at $1608(\mathrm{~s}), 1500(\mathrm{w}), 1378(\mathrm{~s}), 1315(\mathrm{~s}), 1250(\mathrm{~m}), 1213$ (sh), 1076 (m), 1049 (m), 973 (m), 934 (s), 873 (sh), 695 (w) and $634(\mathrm{w}) \mathrm{cm}^{-1}$. These bands are in agreement with the spectrum previously described of polypyrrole in its oxidized form, which shows the presence of polarons and bipolarons ${ }^{31,32}$ (bands at 1378, 1250, 1076 and $973 \mathrm{~cm}^{-1}$ ). These bands are not observed in the reduced polypyrrole spectrum and are attributed to the mobile species in polypyrrole 31,32 .

Similarly, polyaniline was also polymerized using CAA as oxidant, resulting in CAA/PANI-1 hybrid material. The green color of the final product is an evidence for polyaniline formation in its conducting state, emeraldine salt (ES). CHN elemental analysis indicates that the amount of polymer in the hybrid material is $3.2 \%$ in weight after $72 \mathrm{~h}$ of reaction. Figure 2 shows the FTIR spectrum of the CAA/PANI-1 composite (c). The spectra of the pure CAA (a) and pure polyaniline-ES (b) are also presented. Comparison of the CAA/PANI-1 and pure polyaniline spectra indicates that the emeraldine salt form is present in our composite, with bands at $1611,1567,1470,1295,1240$ and $1130 \mathrm{~cm}^{-1}$ (see doted lines in Figure 2). The ES formation in our hybrid material was also confirmed by Raman spectroscopy. Figure 3 shows the Raman spectra of CAA (a) and CAA/PANI-1 (b), with the characteristic bands of polyaniline $-\mathrm{ES}^{33}$.

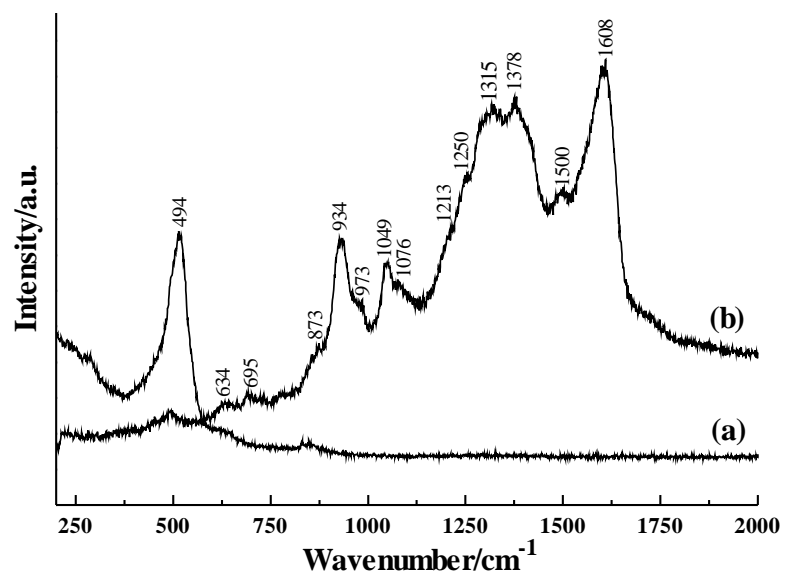

Figure 1. Raman spectra of (a) CAA; (b) CAA/PPy.

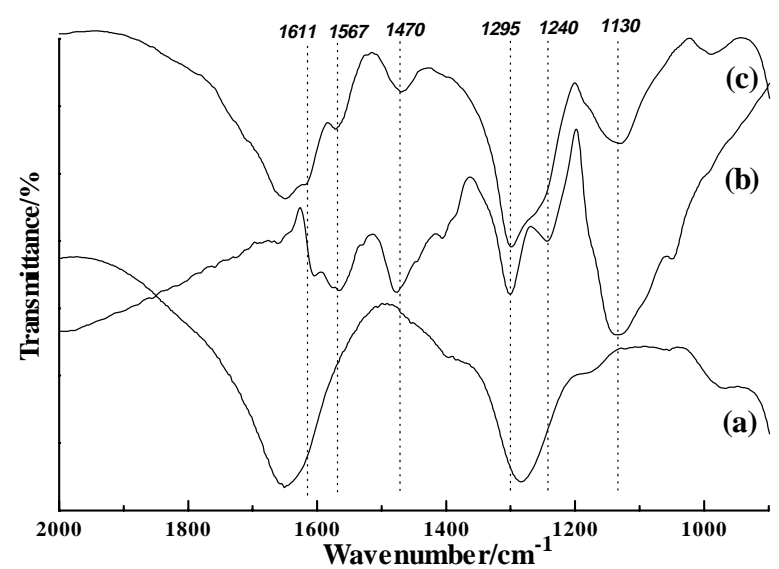

Figure 2. Infrared spectra of (a) CAA; (b) pure polyaniline, emeraldine salt; (c) CAA/PANI-1. Doted line represents the bands of polyanilineemeraldine salt present in the CAA/PANI-1 hybrid.

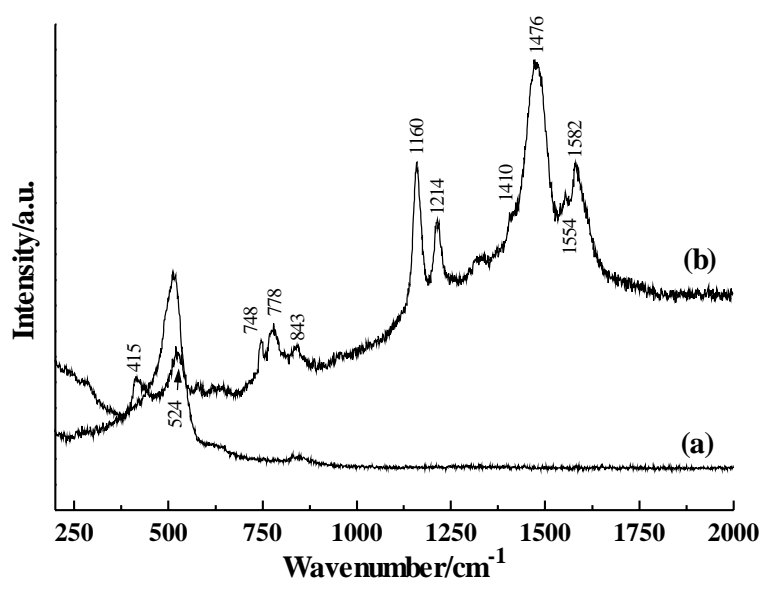

Figure 3. Raman spectra of (a) CAA; (b) CAA/PANI-1. 
Cyclic voltammetry experiments were carried out to test the electroactivity of the hybrids in comparison to pure polymers. The CAA voltammogram shows high capacitive current and no associated redox process in the studied potential range of -0.2 to $0.8 \mathrm{~V}$. The typical redox process attributed to oxidation/reduction of the polyaniline was observed in the voltammogram curve of the CAA/PANI-1 hybrid obtained in this work (Figure 4). The CAA/PANI-1 voltammogram shows two well-defined reversible redox processes characteristic of PANI, indicating that despite the lower amount of polymer present in this hybrid, it does present electroactivity. However, this was not similar in the CAA/PPy voltammogram, where no redox process was observed.

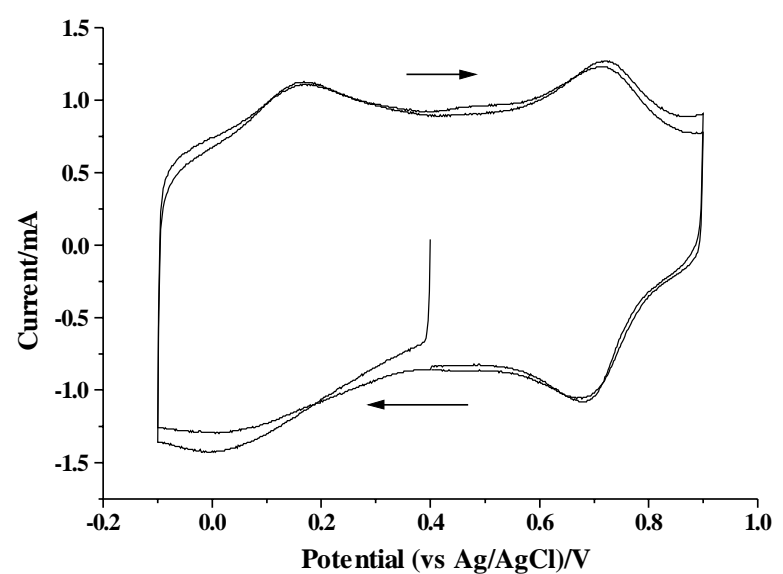

Figure 4. Cyclic voltammetry of the hybrid CAA/PANI-1 (vs Ag/AgCl, scan speed $50 \mathrm{mV} \mathrm{s}^{-1}$ ).

Figure 5-a shows the X-ray pattern of CAA. It is typical of a cubic pyrochlore-like structure ${ }^{28}$ and shows that the solid is well crystallized. The XRD patterns of both CAA/ PPy and CAA/PANI-1 hybrids, shown in Figures 5-b and 5-c, respectively, do not exhibit marked differences with respect to pure CAA pattern. This result could be taken as evidence that no structural changes occur in the CAA pyrochlore network due to the presence of the polymer. In other words, these results indicate that the $\left[\mathrm{Sb}_{2} \mathrm{O}_{6}{ }^{2-}\right]_{\mathrm{n}}$ threedimensional framework characteristic of the pyrochlore structure is present in the final hybrid materials, and this structure can be acting as a counter-anion in the polymer chain. This last statement will be discussed further below.

EPR experiments were carried out to understand the nature of carriers in the polymer formed in our hybrid materials. Figure 6 shows the EPR spectra of both CAA/ PPy (a) and CAA/PANI-1 (b) materials. A free radical peak appeared in the EPR spectra of both hybrids, indicating the presence of polarons in these samples ${ }^{34,35}$. No free radical signal was found in the EPR spectra of the pure CAA. In the CAA/PPy spectra, the $g$ value observed was 2.0045 and the peak-to-peak linewidth $(\Delta \mathrm{B})$ was $8.3 \mathrm{G}$. In the CAA/PANI-1, the values were $\mathrm{g}=2.0048$ and $\Delta \mathrm{B}=2.9 \mathrm{G}$.



Figure 5. X-Ray diffractograms of (a) CAA; (b) CAA/PPy; (c) CAA/PANI-1.

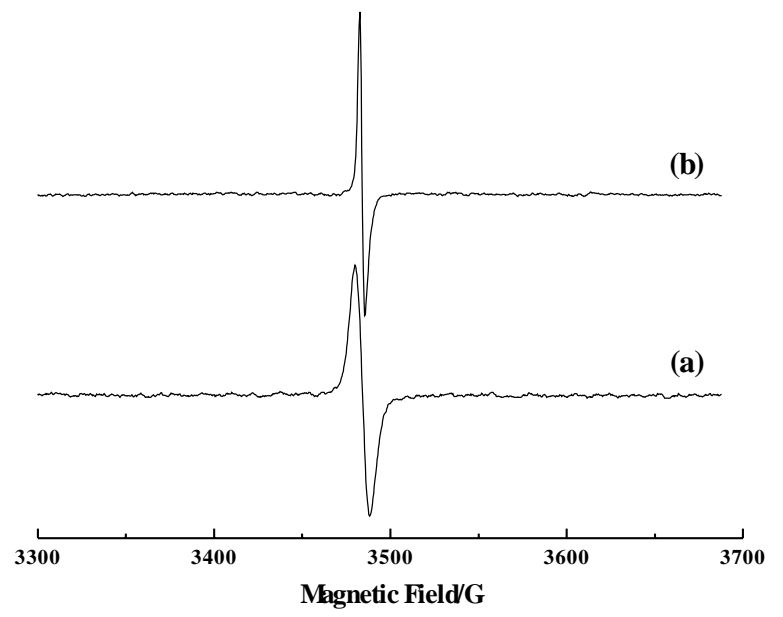

Figure 6. EPR spectra of (a) CAA/PPy; (b) CAA/PANI-1.

It has been proposed that polarons are generated by adding $\mathrm{H}^{+}$to the $\beta$-position of the pyrrole ring during the in situ doping polymerization of pyrrole ${ }^{36}$. The presence of polaron in our CAA/PPy hybrid constitutes strong evidence that the CAA could be a sufficiently strong acid to dope polypyrrole with protons. In this case the $\left[\mathrm{Sb}_{2} \mathrm{O}_{6}{ }^{2-}\right]_{n}$ framework acts as the counter-anion in our system. The absence of any other anionic species in the reaction corroborates this hypothesis. According to this we propose the following model for the formation of our CAA/PPy hybrid: i) the polymerization begins with pyrrole oxidation initiated by the reduction of $\mathrm{Sb}(\mathrm{V})$ present in the CAA to $\mathrm{Sb}$ (III); ii) because the reaction is carried out in air, oxygen could be acting as an indirect oxidant of Sb (III) back to 
$\mathrm{Sb}(\mathrm{V})$ during the reaction. This effect has been observed in other cases ${ }^{37,38}$. In PANI polymerization with $\mathrm{V}_{2} \mathrm{O}_{5}$, for example, the decrease in oxygen concentration during the reaction was confirmed by monitoring oxygen uptake ${ }^{38}$; iii) during the in situ polymerization, the formed polypyrrole is oxidized and protonated by the CAA, resulting in a doped polymer, with a pyrochlore $\left[\mathrm{Sb}_{2} \mathrm{O}_{6}{ }^{2-}\right]_{\mathrm{n}}$ acting as a counter-anion. The detection of the polaron signal by EPR was fundamental to corroborate this model. Similar steps have been proposed to explain the formation of materials between polypyrrole and polyaniline with phosphomolibdic acid, resulting in organic-inorganic hybrids with the phosphomolybdate anion as dopant in conducting polymers $37,39,40$.

The mode of formation of the CAA/PANI- 1 hybrid is not so clear. In this case, we cannot affirm that $\left[\mathrm{Sb}_{2} \mathrm{O}_{6}{ }^{2-}\right]_{\mathrm{n}}$ acts as a counter anion to the ES, once there are $\mathrm{Cl}^{-}$ions present in the reaction medium. Attempts to obtain CAA/ PANI hybrids in the absence of $\mathrm{HCl}$ were carried out (see Experimental). All these attempts produced pink samples that were not characterized. These experiments, however, showed that the CAA is not sufficiently acid to dope the PANI with protons. Wu and Bein observed a pink product when aniline vapor was adsorbed on $\mathrm{Cu}^{2+}$ exchanged aluminosilicate MCM-41, which was attributed to a mixture of quite reactive radicals and cations of aniline or its oligomers ${ }^{41}$.

In conclusion, we have presented herein the synthesis and characterization of two new hybrid materials of conducting polymer and antimonic acid, formed by in situ polymerizations of pyrrole and aniline. The role of CAA in the formation process was discussed for the CAA/PPy case, showing that it acts as an oxidant and dopant in the final product. Another possibility that cannot be discarded is directly related to the CAA structure. The pyrochlorelike structure forms a framework with interconnected interstitial cavities, with dimensions close to those of a pyrrole ring. In the CAA/PPy case, it is possible that the pyrrole polymerization has occurred inside these cavities, as described by Bein and Enzel ${ }^{14}$ that obtained conducting polymers as single chains inside zeolite structures. This would explain the small amount of polymer formed in our CAA/PPy material. However, we have no experimental evidence to indicate that polypyrrole was formed on the crystal surface or within the CAA cavities system.

\section{Acknowledgments}

The authors would like to thank LACTEC by XRD, Laboratório de Espectroscopia Molecular (USP-SP) by the Raman spectra, Prof. L. H. Mascaro (DQ-UFPR) for the voltammogram discussion, G.R. Friedermann and Prof. A.S. Mangrich, from LabEPR (DQ - UFPR) by the EPR spectra, CNPq (Process 461683/00-8), Fundação Araucária and FDA-UFPR for financial support. F. B. thanks also CNPq/PIBIC for a fellowship.

\section{References}

1. Judeinstein, P.; Sanchez, C. J. Mater. Chem. 1996, 6,511 .

2. Asefa, T.; Yoshina-Ishii, C.; MacLachlan M. J.; Ozin G.A. J. Mater. Chem. 2000, 10, 1751.

3. Boury, B.; Corriu, R. J. P. Adv. Mater. 2000, 12, 989.

4. Kimizuka, N.; Kunitake, T. Adv. Mater. 1996, 8, 89.

5. Giannelis, E. P. Adv. Mater. 1996, 8, 29.

6. Kryszewski, M. Synth. Met. 2000, 109, 47.

7. Backov, R.; Bonnet, B.; Jones, D. J.; Rozière, J. Chem. Mater. 1997, 9, 1812.

8. Wen, J.; Wilkes, G. L. Chem. Mater. 1996, 8, 1667.

9. Toledo, E. A.; Gushiken, Y.; De Castro, S. C. J. Colloid Interf. Sci. 2000, 225, 455.

10. Chen, J. I.; Chareonsak, R.; Puengpipat, V.; Marturunkakul, S. J. Appl. Polym. Sci. 1999, 74, 1341.

11. Zarbin, A. J. G.; De Paoli, M. -A.; Alves, O. L. Synth. Met. 1999, 99, 227.

12. Gonçalves, A. B.; Mangrich, A. S.; Zarbin, A. J. G. Synth. Met. 2000, 114, 119.

13. Kerr, T. A.; Wu, H.; Nazar, L. F. Chem. Mater. 1996, 8, 2005

14. Bein, T.; Enzel, P. Angew. Chem. Int. Ed. Engl. 1989, 28, 1692.

15. Lira-Cantú, M.; Gómez-Romero, P. Chem. Mater. 1998, 10, 698.

16. MacDiarmid, A. G.; Yang, L. S.; Huang, W. S.; Humphrey, B. D. Synth. Met. 1987, 18, 393.

17. Bäurle, P. Adv. Mater. 1993, 5, 879.

18. Salaneck, W. R.; Lundstron, I.; Huang, W. S.; MacDiarmid, A. G. Synth. Met. 1986, 13, 291.

19. Brédas, J. L.; Street, G. B. Acc. Chem. Res. 1985 , $18,309$.

20. Jang, S. H.; Han M. G.; Im S. S. Synth. Met. 2000, $110,17$.

21. Mehrotra, V.; Keddie, J. L.; Miller, J. M.; Giannelis, E. P. J. Non-Crystalline Solids 1991, 136, 97.

22. Wei, Y.; Yeh, J. -M.; Jin, D.; Jia, X.; Wang, J.; Jang, G. -W.; Chen, C.; Gumbs, R. W. Chem. Mater. 1995, 7, 969.

23. Hori, T.; Kuramoto, N.; Tagaya, H.; Karasu, M.; Kadokawa, J.; Chiba, K. J. Mater. Res. 1999, 147.

24. Ruiz-Hitzky, E.; Aranda, P. An. Quim-Int. Ed. 1997, 93, 197. 
25. Maia, D. J.; De Paoli, M. -A.; Alves, O. L.; Zarbin, A. J. G.; Neves, S. Quim. Nova 2000, 23, 204.

26. Zarbin, A. J. G.; Alves, O. L. J. Mater. Chem. 1994, 4, 389.

27. Zarbin, A. J. G.; Alves, O. L.; Amarilla, J. M.; Rojas, R. M.; Rojo, J. M. Chem. Mater. 1999, 11, 1652.

28. England, W. A.; Cross, M. G.; Hamnet, A.; Einsman, P. J.; Goodenough, J. B. Solid State Ionics 1980, 1, 231.

29. Barthet, C.; Guglielmi, M. J. Electroanal. Chem. 1995, 388, 35.

30. Ozawa, Y.; Miura, N.; Yamazoe, N.; Seyama, T. Chem. Lett. 1982, 1741.

31. Furukawa, Y.; Tazawa, S.; Fujii, Y.; Harada, I. Synth. Met. 1988, 24, 329.

32. Zhong, C. J.; Tian, C. Q.; Tian, Z. W. J. Phys. Chem. 1990, 94, 2171.
33. Furukawa, Y.; Hara, T.; Hyoto, Y.; Harada, I. Synth. Met. 1989, 16, 189.

34. Bartl, A.; Dunsch, L.; Naarmann, H.; Schmeiber, D.; Göpel, W. Synth. Met. 1993, 61, 167.

35. Larsen, G.; Haller, G. L.; Marquez, M. J. Phys. Chem. 1992, 96, 4145.

36. Shen, Y.; Wan, M. Synth. Met. 1998, 96, 127.

37. Gomez-Romero, P.; Lira-Cantú, M. Adv. Mater. 1997, 9, 144.

38. Wu, C. -G.; DeGrrot, D. C.; Marcy, H. O.; Schindler, J. L.; Kannewurf, C. R.; Liu, Y. J.; Hirpo, W.; Kanatzidis, M. G. Chem. Mater. 1996, 8, 1992.

39. Lira-Cantú, M.; Gómez-Romero, P. Chem. Mater. 1998, 10, 698.

40. Hasik, M.; Pron, A.; Raynor, J. B.; Luzny, W. New J. Chem. 1995, 19, 1155.

41. Wu, C. -G.; Bein, T. Chem. Mater. 1994, 6, 1109.

Received: November 30, 2000

Published on the web: July 12, 2001 